\title{
El incremento de la población reclusa en España entre 1996- 2006: Diagnóstico y remedios ${ }^{1}$
}

\author{
José Cid \\ Profesor titular de Derecho Penal \\ Universidad Autónoma de Barcelona.
}

\begin{abstract}
RESUMEN
En 2003-2004 el Grupo de Estudios de Política Criminal elaboró un proyecto de reforma del sistema de penas y de su ejecución. La propuesta de este grupo de orientación progresista -integrado por profesores/as de derecho penal y jueces/zaspartía de un diagnóstico negativo del sistema punitivo en España, al que se culpaba del incremento de la tasa de encarcelamiento a partir de la implementación del Código Penal de 1995. En este artículo se exploran las razones del incremento de la población penitenciaria entre 1996-2006, se analiza la capacidad del proyecto reduccionista presentado por este grupo de invertir la tendencia y se discuten posibles objeciones a esta propuesta político-criminal.
\end{abstract}

Palabras clave: Tasas de encarcelamiento. Políticas reduccionistas. Grupo de Estudios de Política Criminal. España. 1996-2006

\footnotetext{
${ }^{1}$ Una versión inicial del texto que se expone a continuación fue presentado en la mesa redonda sobre "La necesaria reforma del sistema de penas", dentro del curso organizado por el Consejo General del Poder Judicial, relativo a "Algunas cuestiones problemáticas de la actual Política criminal", dirigido por Félix Pantoja García y por José Luis Díez Ripollés (La Coruña, 27 junio 2007). Su elaboración se integra en el proyecto de investigación subvencionado por el Ministerio de Educación y Ciencia "La credibilidad de las penas alternativas" (SEJ2005-08955-C02-01) y también ha contado con la ayuda prestada por la Generalitat de Cataluña a los grupos de investigación consolidados (Grupo de Investigación en Criminología Aplicada a la Penología, resolución AGAUR, 18 octubre 2005, SGR 08024). Agradezco a la Administración Penitenciaria del Estado, y en particular a Virgilio Valero, y a la Administración Penitenciaria catalana, y en particular a Albert Batlle, su amabilidad al suministrarme la información estadística solicitada. En la elaboración del trabajo me he beneficiado mucho de la discusión con Elena Larrauri, con quien, contemporáneamente, he realizado un trabajo, en curso de publicación, de más amplio alcance, sobre los factores que inciden en la evolución del encarcelamiento en España desde la transición democrática (Cid y Larrauri, 2007). Lorena Antón, como técnica de apoyo a la investigación, ha prestado una ayuda muy valiosa en la obtención y codificación de los datos estadísticos que aparecen en el trabajo. Agradezco, además, las sugerencias aportadas por Daniel Varona. Pese a que todas estas personas han contribuido a mejorar el trabajo, los errores que puedan existir son de mi exclusiva responsabilidad.
}

Revista Española de Investigación Criminológica

Artículo 2, Número 6 (2008) $\quad$ www.criminología.net

ISSN: 1696-9219 


\begin{abstract}
In the years 2003 and 2004 a liberal Spanish association of criminal law professors and criminal judges (Grupo de Estudios de Política Criminal) made a paper proposing some reforms of the Spanish sentencing system. The proposal was based on a negative vision of the evolution of sentencing in Spain, which was blamed for the increase in incarceration rates since the implementation of the new criminal code of 1995. The present paper explores the reasons of the increase of the prison population from 1996 until 2006, analyses the capacity of the reductionist proposals made by this Spanish association to revert the trends and discus possible objections to this kind of policy.
\end{abstract}

Keywords: Incarceration Rates. Reductionist policies. Grupo de Estudios de Política Criminal. Spain. 1996-2006.

\title{
1. Introducción
}

El objetivo de este trabajo es analizar las razones del incremento del encarcelamiento producido en España entre 1996 y 2006, tomando como base de análisis el diagnóstico y las propuestas realizadas por el Grupo de Estudios de Política Criminal en su propuesta relativa al "Sistema de Penas y su ejecución, y a las medidas cautelares personales"(GEPC 2005).

En su análisis de la evolución punitiva española el Grupo de Estudios de Política Criminal consideraba que España, comparativamente al resto de países europeos, estaba avanzando en las tasas de encarcelamiento y que ello era debido fundamentalmente a tres razones: el incremento de penas por parte del nuevo Código penal (CP 1995), la insuficiente utilización de las nuevas penas alternativas previstas por este código y la aplicación minoritaria los mecanismos de reeducación y reinserción previstos por la legislación penal y penitenciaria (GEPC 2005).

Atendiendo a lo que ha sucedido hasta el presente podemos decir que el Grupo de política criminal acierta en lo que hace al análisis de los tres factores que han contribuido al incremento del encarcelamiento, aun cuando posiblemente se deba añadir un cuarto aspecto consistente en las reformas penales del 2003 y 2004 por lo que hace principalmente al endurecimiento de las penas en materia de violencia doméstica. 
A continuación procedemos a examinar con detalle qué parte de responsabilidad del incremento del encarcelamiento en estos años corresponde a cada uno de los cuatro factores señalados.

\section{Diagnóstico sobre las causas del incremento de la población reclusa}

Con el objetivo de explicar la situación de incremento de la tasa de encarcelamiento que se refleja en la tabla 1, de acuerdo a la cual el número de personas encarceladas ha subido en un 43\% entre 1996 y 2006, vamos a proceder a contrastar los factores que, de acuerdo al GEPC, habrían influido.

Tabla 1. Población reclusa. España (1996-2006)

\begin{tabular}{|l|l|l|l|l|}
\hline & & & TOTAL & $\begin{array}{l}\% \text { reclusos-as } \\
\text { por } \\
\text { habitantes }\end{array}$ \\
\hline 1996 & $10.588(23.9 \%)$ & $33.724(76.1 \%)$ & 44.312 & 112 \\
\hline 1997 & $11.083(25.5 \%)$ & $33.370(74.5 \%)$ & 43.452 & 109 \\
\hline 1998 & $11.272(25.2 \%)$ & $33.475(74.8 \%)$ & 44.747 & 112 \\
\hline 1999 & $10.576(23.3 \%)$ & $34.830(76.7 \%)$ & 45.406 & 113 \\
\hline 2000 & $9.729(21.5 \%)$ & $35.580(78.5 \%)$ & 45.309 & 112 \\
\hline 2001 & $10.006(21.4 \%)$ & $36.588(78.6 \%)$ & 46.594 & 113 \\
\hline 2002 & $11.340(22.6 \%)$ & $38.769(77.4 \%)$ & 50.109 & 121 \\
\hline 2003 & $12.383(22.7 \%)$ & $42.082(77.3 \%)$ & 54.465 & 128 \\
\hline 2004 & $12.994(22,5 \%)$ & $45.661(77,5 \%)$ & 58.655 & 136 \\
\hline 2005 & $13.826(22,8 \%)$ & $46.881(77,2 \%)$ & 60.707 & 138 \\
\hline 2006 & $14.580(23 \%)$ & $48.668(77 \%)$ & 63.248 & 141 \\
\hline
\end{tabular}

FUENTE: Elaboración propia sobre la siguiente base: Ministerio del Interior, Dirección General de Instituciones Penitenciarias (DGIP), Número de internos en los centros penitenciarios. Evolución semanal; Generalitat de Cataluña, Secretaría de Servicios Penitenciarios, Rehabilitación y Justicia Juvenil (SSPRJJ), Estadístiques setmanals de població reclusa. Para las cifras de población en España: INE, Padrón municipal de habitantes.

\subsection{El incremento de penas por parte del Código penal de 1995}

La primera cuestión que debemos plantearnos, antes de culpar al CP 1995 del aumento de personas encarceladas, es si, el crecimiento de la población reclusa no se debe más bien a que se haya producido un aumento de la criminalidad o/y de la actividad policial y judicial que haya comportado, como consecuencia, que, durante estos años, un número creciente de personas hayan ingresado en la cárcel, siendo ésta la causa del aumento de la población reclusa.

Revista Española de Investigación Criminológica

Artículo 2, Número 6 (2008) $\quad$ www.criminología.net

ISSN: 1696-9219 
No obstante, tal como se muestra en la tabla 2, el análisis de la evolución de las entradas en prisión no avala esta posible interpretación, por cuanto entre 1996 y 2005 se produce una reducción del número de entradas en prisión y es sólo a partir de 2006 cuando éstas aumentan.

Tabla 2. Entradas en prisión. España (1996-2006) ${ }^{2}$

\begin{tabular}{|l|l|l|l|l|l|l|}
\hline Año & $\begin{array}{l}\text { Entradas } \\
\text { preventivos/ } \\
\text { as }\end{array}$ & $\begin{array}{l}\% \text { Entradas } \\
\text { preventivos/as }\end{array}$ & $\begin{array}{l}\text { Entradas } \\
\text { condenados/ } \\
\text { as }\end{array}$ & $\begin{array}{l}\% \text { Entradas } \\
\text { condenados/as }\end{array}$ & $\begin{array}{l}\text { Total } \\
\text { Entradas }\end{array}$ & $\begin{array}{l}\% \\
\text { Entradas } \\
100.000 \\
\text { habitantes }\end{array}$ \\
\hline 1996 & 36.627 & 69,6 & 16.028 & 30,4 & 52.655 & 130 \\
\hline 1997 & 34.978 & 62,7 & 20.764 & 37,3 & 55.742 & 140 \\
\hline 1998 & 31.724 & 59,3 & 21.740 & 40,7 & 53.464 & 134 \\
\hline 1999 & 30.217 & 61,7 & 18.796 & 38,3 & 49.013 & 118 \\
\hline 2000 & 27.185 & 65,4 & 14.379 & 34,6 & 41.564 & 103 \\
\hline 2001 & 27.421 & 66,3 & 13.938 & 33,7 & 41.359 & 101 \\
\hline 2002 & 28.793 & 69,0 & 12.927 & 31,0 & 41.720 & 100 \\
\hline 2003 & 27.327 & 67,5 & 13.138 & 32,5 & 40.465 & 95 \\
\hline 2004 & 28.412 & 68,1 & 13.313 & 31,9 & 41.725 & 97 \\
\hline 2005 & 28.631 & 72,0 & 11.143 & 28,0 & 39.774 & 89 \\
\hline 2006 & 31.004 & 70,1 & 13.218 & 29,9 & 44.222 & 105 \\
\hline $1996-$ & & & & & & \\
2006 & & 66,5 & & 33,5 & & \\
\hline
\end{tabular}

Fuente: Elaboración propia sobre la siguiente base: DGIP, Estadística General de Población Reclusa. Evolución mensual. Cataluña, Consejería de Justicia. Memòria anual y SSPRJJ, Estadístiques setmanals de població reclusa. INE, Cifras de población.

De esta manera se produce una situación, que podría parecer paradójica, consistente en que, tomando como base 1996, la cifra de entradas en prisión se ha reducido de manera significativa (un $20 \%$ menos de entradas de media en el período 2000-2005) y sin embargo es justamente en estos años cuando se produce la tendencia ascendente en el número de personas encarceladas (Figura 1).

\footnotetext{
${ }^{2}$ El hecho de que exista un porcentaje tan bajo de personas que entran en prisión como condenadas no significa que sólo existan estas condenas a prisión por año, sino que la mayoría de personas que son condenadas a prisión (ejecutada) no son alta en prisión porque ya se encuentran en situación de prisión preventiva.
}

Revista Española de Investigación Criminológica

Artículo 2, Número 6 (2008) $\quad$ www.criminología.net

ISSN: $1696-9219$ 


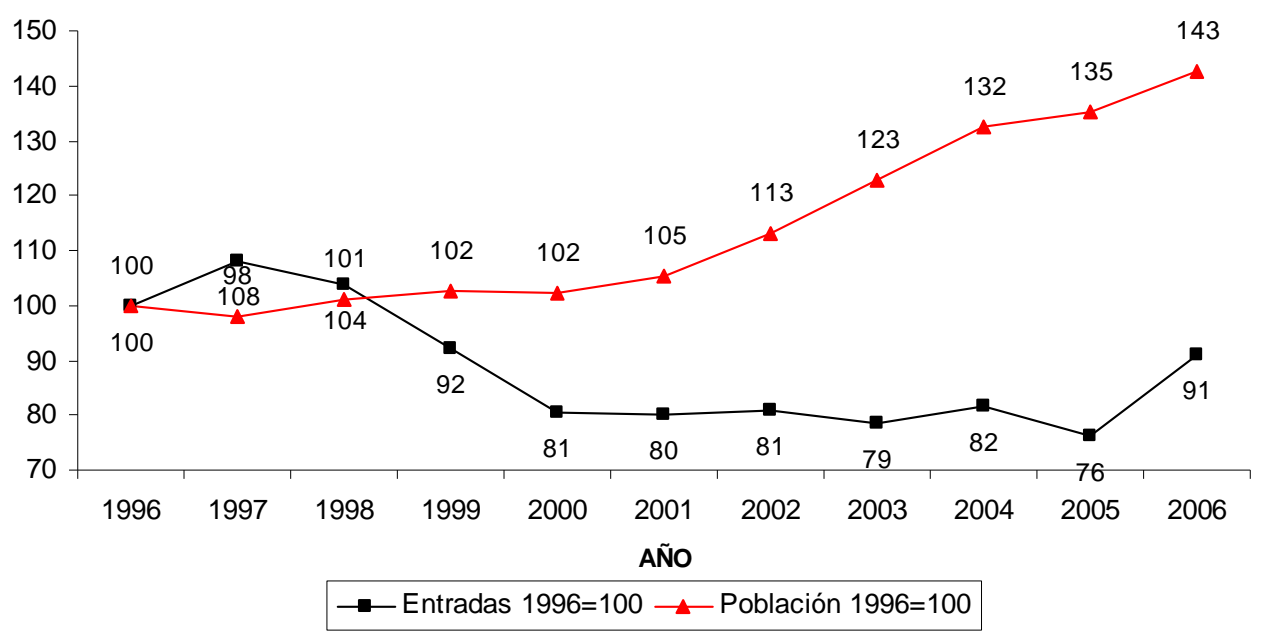

Figura 1. Entradas en prisión-Población reclusa. España (1996-2006)

Si las entradas en prisión no ha sido el factor que ha alimentado el incremento de las personas encarceladas, ello parece significar que las personas encarceladas han permanecido más tiempo del que lo hacían antes de la entrada en vigor del CP 1995. Que ello sea así parece lógico atendiendo a que éste Código, por una parte, subió las penas de algunos de los delitos que tienen una importante representación en la actividad judicial y, por otra, abolió la redención de penas por el trabajo que acortaba el tiempo efectivo de cumplimiento de condena en 1/3 con carácter general y hasta a 1/2 en atención a la participación en el tratamiento u otras actividades en el ámbito penitenciario (Navarro 1997) ${ }^{3}$. En la tabla 3 se hace una comparativa de las penas mínimas efectivas a cumplir de acuerdo al Código penal de 1973 (en consideración a las reformas de 1983 y 1988) y del código penal de 1995.

\footnotetext{
${ }^{3}$ Tamarit (2007:30) destaca que no es sólo la eliminación de la redención de penas por el trabajo (al que se hace referencia en Cid 2005a) sino también la elevación de penas para algunos delitos lo que ha llevado al incremento del encarcelamiento.
}

Revista Española de Investigación Criminológica

Artículo 2, Número 6 (2008) $\quad$ www.criminología.net

ISSN: 1696-9219 
Tabla 3. Comparativa de penas Código penal de 1973 (y sucesivas reformas) y CP 1995

\begin{tabular}{|l|l|l|l|l|}
\hline \multirow{2}{*}{ DELITOS } & \multicolumn{2}{l}{$\begin{array}{l}\text { CÓDIGO PENAL DE 1973 (CON CÓDIGO } \\
\text { REFORMAS SUCESIVAS 1983 y 1988) }\end{array}$} & $\begin{array}{l}\text { CÓDENAL 1995 } \\
\text { PEN }\end{array}$ \\
\cline { 2 - 5 } & $\begin{array}{l}\text { Pena } \\
\text { mínima }\end{array}$ & $\begin{array}{l}\text { Pena mínima } \\
\text { efectiva } \\
\text { (con } \\
\text { redención } \\
\text { ordinaria) }\end{array}$ & $\begin{array}{l}\text { Pena mínima } \\
\text { efectiva } \\
\text { (con redención } \\
\text { ordinaria y } \\
\text { extraordinaria) }\end{array}$ & $\begin{array}{l}\text { Pena mínima } \\
\text { efectiva }\end{array}$ \\
\hline Hurto & 1 mes & 20 días & 15 días & 6 meses \\
\hline Robo con fuerza & 6 meses & 4 meses & 3 meses & 1 año \\
\hline Robo en casa habitada & 50 meses & 36 meses & 25 meses & 24 meses \\
\hline Robo & 6 meses & 4 meses & 3 meses & 24 meses \\
\hline Robo armado & 50 meses & 36 meses & 25 meses & 42 meses \\
\hline Tráfico de drogas (duras) & 28 meses & 18 meses & 14 meses & 36 meses \\
\hline Lesiones & 1 mes & 20 días & 15 días & 6 meses \\
\hline Violación & 12 años & 8 años & 6 años & 6 años \\
\hline Homicidio & 12 años & 8 años & 6 años & 10 años \\
\hline
\end{tabular}

Nota: Delitos básicos sin circunstancias agravantes ni atenuantes. Sin considerar libertad condicional. A efectos de comparación, se considera un hurto, robo con fuerza o robo en casa habitada de $300 €$.

Como consecuencia de este nuevo marco penológico, el tiempo medio de estancia en prisión se ha casi duplicado desde la vigencia del nuevo Código penal, pasado de 9.7 meses en 1996 a 16.7 meses en 2004 (Consejo de Europa, Space, 2005, 13.1).

En síntesis, de acuerdo a los datos anteriores parece correcto el diagnóstico del GEPC en el sentido de que ha sido el endurecimiento de las penas producido por el CP 1995- en el doble sentido de penas nominalmente más elevadas para determinados delitos y de eliminación de la redención de penas por el trabajo- el principal responsable de que se haya producido este importante incremento de la población reclusa entre 1996 y $2006^{4}$.

\footnotetext{
${ }^{4}$ Puede sorprender que si se atribuyen los efectos del incremento de la población reclusa al Código Penal de 1995, el crecimiento importante sólo se produzca a partir de 2001. Ello se debe, según creo, a que en los primeros años de aplicación del CP de 1995, las personas en prisión lo están mayoritariamente por hechos cometidos bajo la vigencia del CP de 1973, juzgados de acuerdo a este código penal y, por tanto, beneficiándose de la redención de penas por el trabajo. En la medida en que se va invirtiendo la tendencia, aumentando el porcentaje de personas que cumple condena de acuerdo al CP de 1995, se va reduciendo el número de salidas por año y, consiguientemente, se incrementa la población reclusa.
}

Revista Española de Investigación Criminológica

Artículo 2, Número 6 (2008) $\quad$ www.criminología.net

ISSN: 1696-9219 


\subsection{La insuficiente aplicación de las nuevas penas alternativas previstas por el Nuevo Código Penal}

El GEPC consideró que las nuevas penas alternativas a la prisión previstas por el Nuevo Código Penal no se estaban aplicando suficientemente y que ello era el segundo factor que contribuía a explicar las elevadas tasas de encarcelamiento en España.

Como es sabido, el CP 1995 realizó las siguientes innovaciones principales en el sistema de penas alternativas:

a) ampliar la posibilidad suspensión ordinaria de la pena, que estaba situada en 1 año de prisión, hasta condenas de 2 años de prisión;

b) elevar la posibilidad de suspensión especial para drogodependientes, que estaba situada en dos años de prisión, hasta 3 años de prisión;

c) admitir la posibilidad de sustitución de la pena privativa de libertad de hasta 2 años, por multa o en caso de que la condena fuera Arresto de fin de semana, trabajo en beneficio de la comunidad, aunque la persona dispusiera de antecedentes penales;

d) establecer que tanto la suspensión como la sustitución de la pena pudieran ir acompañadas de reglas de conducta, admitiendo una cierta modalidad de probation.

No obstante, el hecho de que se haya producido una importante reducción de las entradas en prisión tras la aprobación del Nuevo Código Penal, que ha durado hasta 2005, obliga a analizar en profundidad la certeza del diagnóstico del GEPC, pues cabe plantearse si no es justamente la aplicación de las nuevas penas alternativas previstas por este código lo que ha llevado a una reducción de las entradas en prisión, contribuyendo, más bien, a reducir el encarcelamiento.

\subsubsection{Explicación de la reducción de entradas en prisión en el periodo 1996-2005}

Existen cuatro explicaciones posibles para entender la reducción de entradas en prisión que se produce a partir de la entrada en vigor del CP 1995: a) Reducción del número de condenas penales por delito; b) Reducción del número de condenas a pena 
privativa de libertad; c) Aumento del uso de la suspensión y sustitución de penas privativas de libertad; d) Reducción del uso de la prisión preventiva.

Procedemos a continuación, de manera ordenada, a analizar estas cuatro hipótesis.

\section{a) Reducción de condenas penales por delito}

El análisis de la evolución de las condenas por delito (Figura 2) muestra que, en efecto, una parte de la reducción de entradas en prisión se debe a que, en los primeros años de aplicación del CP 1995 (1996-1998) el número de personas condenadas se sitúa de media en 107.000 mientras que en los años siguientes (1999-2002) se reduce de media a 99.000 .

No obstante, este descenso del número de personas condenadas (en torno al 8\%) no parece suficiente para explicar la disminución de entradas en prisión en un $20 \%$ que se produce comparando el periodo 1996-1999 (52.000 entradas anuales de media) y el periodo 2000-2005 (41. 000 entradas anuales de media)

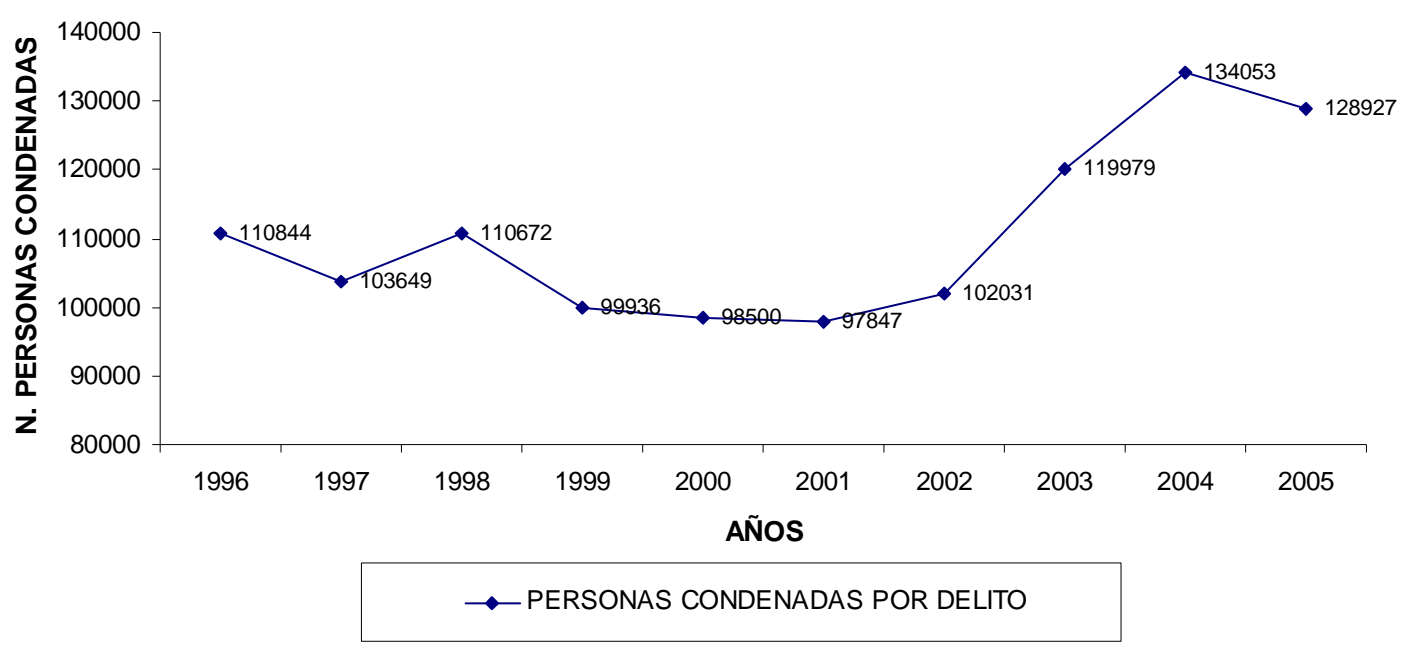

Figura 2. Personas condenas por delitos. España (1996-2005)

Fuente: INE. Estadísticas judiciales. Personas condenadas por delito

Dado que la contracción del número de entradas en prisión se explica sólo de manera parcial por el hecho de que se haya producido un menor número de personas 
condenadas por delito (entre 1999 y 2002) ello obliga a considerar el resto de hipótesis señaladas.

\section{b) Reducción del número de condenas a pena privativa de libertad}

Tal como se muestra en la figura 3 , no parece existir una tendencia a la disminución del porcentaje de condenas a pena privativa de libertad durante este período que pueda explicar suficientemente la reducción de entradas en prisión. Más bien se advierte una cierta estabilidad en el porcentaje de condenas a esta clase de penas durante todo el periodo analizado.

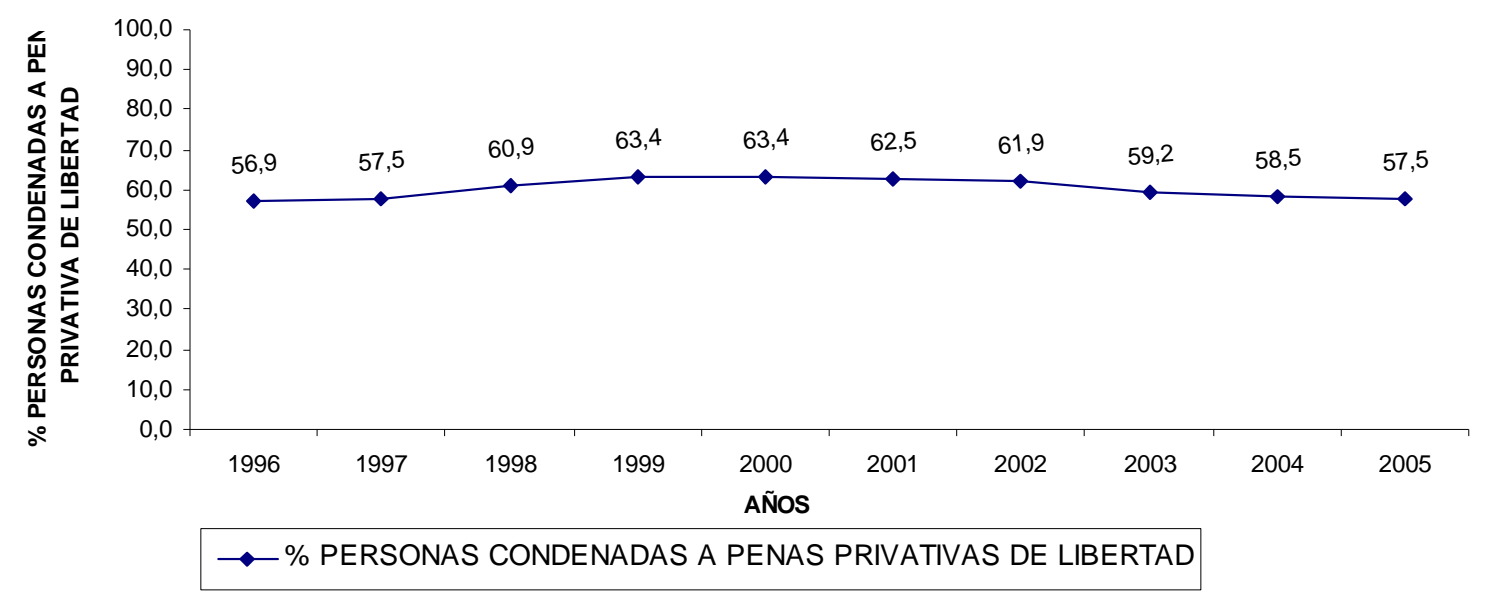

Figura 3. Porcentaje de personas condenadas por delito a pena privativa de libertad. España (1996-2005) ${ }^{5}$

Fuente: INE. Estadísticas judiciales.

Si el porcentaje de condenas a pena privativa de libertad se mantiene bastante estable en el periodo 1996-2006 y, no obstante, se produce una reducción de las entradas en prisión ello obliga a tomar en consideración el resto de factores posibles.

\section{c) Aumento de las penas privativas de libertad suspendidas o sustituidas}

A favor de la hipótesis de que a partir de la aprobación del CP 1995 se ha producido un mayor uso de la suspensión y sustitución de la pena se pude aducir la reducción muy significativa del número de entradas en prisión en referencia a las

\footnotetext{
${ }^{5}$ En sus estadísticas de personas condenadas, el INE contabiliza una única pena por persona condenada. Se han computado todos los casos en que la pena que aparece es privativa de libertad. Sobre la forma de computar las penas por el INE véase las observaciones de Varona (2004:3) y de Tamarit (2007:29).
}

Revista Española de Investigación Criminológica

Artículo 2, Número 6 (2008) $\quad$ www.criminología.net

ISSN: $1696-9219$ 
personas condenadas a pena privativa de libertad. Tal como se muestra en la tabla 4 , mientras que en los años iniciales de aprobación del CP 1995 (1996-1999) este porcentaje se sitúa de media en el $83 \%$ en el periodo posterior (2000-2005) se fija en torno al $60 \%$.

Tabla 4. Evolución personas condenadas a pena privativa de libertad-entradas en prisión. España (1996-2005) ${ }^{6}$.

\begin{tabular}{|l|l|l|l|}
\hline Año & $\begin{array}{l}\text { Personas condenadas } \\
\text { a pena privativa de } \\
\text { libertad }\end{array}$ & Entradas en prisión & $\begin{array}{l}\text { Porcentaje de } \\
\text { entradas en prisión } \\
\text { sobre rersonas } \\
\text { condenadas pena } \\
\text { privativa de libertad }\end{array}$ \\
\hline 1996 & 63.083 & 52.655 & 83,5 \\
\hline 1997 & 59.618 & 55.742 & 93,5 \\
\hline 1998 & 67.378 & 53.482 & 79,4 \\
\hline 1999 & 63.365 & 49.013 & 77,4 \\
\hline 2000 & 62.496 & 41.564 & 66,5 \\
\hline 2001 & 61.111 & 41.359 & 67,7 \\
\hline 2002 & 63.129 & 41.720 & 66,1 \\
\hline 2003 & 71.021 & 40.465 & 57,0 \\
\hline 2004 & 78.394 & 41.725 & 53,2 \\
\hline 2005 & 74.127 & 39.774 & 53,7 \\
\hline
\end{tabular}

Fuente personas condenadas: INE. Estadísticas judiciales.

Las estadísticas judiciales no nos son de ayuda para saber si esta tendencia a la limitación del porcentaje de entradas en prisión en referencia a personas condenadas a pena privativa de libertad, se debe a un mayor uso de la suspensión y sustitución de la pena por cuanto no indican si la pena privativa de libertad impuesta en sentencia ha sido suspendida o sustituida ${ }^{7}$. Es por ello, que la única fuente posible de conocimiento es la que, en referencia exclusiva a suspensiones de condena, suministra el Registro Central de Penados y Rebeldes, en el cual se inscriben tanto las penas privativas de libertad impuestas como los autos de suspensión de penas privativas de libertad.

La tabla 5 parece mostrar que, en efecto, el uso de la suspensión de la pena por parte de jueces/zas y tribunales penales españoles se postula como el principal candidato

\footnotetext{
${ }^{6}$ Para interpretar la tabla es importante advertir que no existe correspondencia de personas, año por año, entre las condenadas a prisión y las que entran en prisión, por cuanto, por ejemplo, de las personas condenadas en 1999, su entrada en prisión (si fue en prisión preventiva) se produjo en años anteriores (normalmente en la fecha cercana al delito cometido) y si fue tras la condena, se producirá en años posteriores, tras la decisión sobre la suspensión o sustitución de la pena. Ello no es óbice para que, a mi juicio, la comparación entre condenas a pena privativa de libertad y entradas en prisión tenga sentido por cuanto, tomando en cuenta una serie de años, se refleja la realidad del porcentaje de personas condenadas a prisión que entran en la institución penitenciaria.

${ }^{7}$ Estos problemas han sido repetidamente denunciados. Véase: Cid, Larrauri et al. (2002), Diez Ripollés (2006), Tamarit (2007).
}

Revista Española de Investigación Criminológica

Artículo 2, Número 6 (2008) $\quad$ www.criminología.net

ISSN: 1696-9219 
para explicar la reducción de entradas en prisión que se produce a partir de la entrada en vigor del CP 1995.

Tabla 5. Inscripciones de penas privativas de libertad y de suspensiones de penas privativas de libertad. España (1996-2006) ${ }^{8}$

\begin{tabular}{|l|l|l|l|}
\hline Año & $\begin{array}{l}\text { Penas privativas de } \\
\text { libertad }\end{array}$ & $\begin{array}{l}\text { Suspensiones de penas } \\
\text { privativas de libertad }\end{array}$ & $\begin{array}{l}\text { Porcentaje suspensiones inscritas } \\
\text { sobre } \\
\text { libertad inscritas }\end{array}$ \\
\hline 1996 & 78.027 & 9.223 & 11,8 \\
\hline 1997 & 84.314 & 10.102 & 12,0 \\
\hline 1998 & 84.090 & 10.180 & 12,1 \\
\hline 1999 & 79.697 & 11.406 & 14,3 \\
\hline 2000 & 75.001 & 14.763 & 19,7 \\
\hline 2001 & 77.527 & 20.677 & 26,7 \\
\hline 2002 & 82.012 & 26.716 & 32,6 \\
\hline 2003 & 94.154 & 34.638 & 36,8 \\
\hline 2004 & 133.866 & 51.894 & 38,8 \\
\hline 2005 & 155.532 & 54.576 & 35,1 \\
\hline 2006 & 150.081 & 33.919 & 22,6 \\
\hline
\end{tabular}

Fuente: Información suministrada al autor por Ministerio de Justicia, Subdirección General de Registros Judiciales en fecha 1 octubre 2007.

En referencia a los datos que muestran la tabla 5, Diez Ripollés (2006:19, n. 70) señala que la evolución la suspensión que se manifiesta, resulta difícilmente explicable sobre la base únicamente del incremento del ámbito de las penas suspendibles de 1 a 2 años por parte del CP 1995 y, en particular, considera poco comprensible, en atención a la información de que se dispone, el gran incremento de la suspensión a partir del año $2000^{9}$. A mi juicio, una posible respuesta a los interrogantes planteados por este autor proviene de tomar en consideración, de manera adicional, la última de las hipótesis aludidas.

\footnotetext{
${ }^{8}$ Para interpretar esta tabla es importante tomar en cuenta que: a) el Registro anota penas privativas de libertad individualmente consideradas (por tanto, por ejemplo, si una persona es condenada a tres penas privativas de libertad en la misma sentencia ello comporta tres inscripciones); b) El registro anota, igualmente, penas suspendidas individualmente consideradas (así, por ejemplo, si en un auto de suspensión se suspenden dos penas entonces constan dos inscripciones de penas suspendidas); c) Las penas privativas de libertad son comunicadas al Registro una vez que alcanzan firmeza y las suspensiones una vez que se dicta el auto firme se suspensión, por lo cual no existe coincidencia, año por año, entre penas inscritas y penas suspendidas, refiriéndose, normalmente, los autos de suspensión a penas inscritas en años anteriores; d) Es posible que el dato tan bajo de autos de suspensión del año 2006 se deba a que muchos autos de suspensión dictados en este año aún no han sido inscritos.

${ }^{9}$ Las opiniones de Diez Ripollés se realizaron en referencia a la exposición de datos de suspensión, con base a la misma fuente que los actuales, referida al periodo 1996-2003 (Cid 2005a). Si bien entre los datos publicados entonces y los que se publican en el presente trabajo existen ciertas diferencias, como consecuencia de las nuevas inscripciones producidas entre las dos solicitudes de información, no obstante, se mantiene la tendencia al incremento de las suspensiones inscritas a partir del año 2000. Véase también, en concordancia con Díez Ripollés, las observaciones realizadas por parte de Tamarit (2007:29).
}

Revista Española de Investigación Criminológica

Artículo 2, Número 6 (2008) $\quad$ www.criminología.net

ISSN: $1696-9219$ 


\section{d) Menor uso de la prisión preventiva}

El uso que se realice de la prisión preventiva tiene una influencia muy importante en las entradas en prisión. En el plano teórico, cabe indicar que las razones por las cuales el mayor o menor uso de la prisión preventiva afecte el número de entradas en prisión son las siguientes. En primer lugar, un uso reducido de la prisión preventiva limita las entradas en prisión de personas que posteriormente son absueltas. En segundo lugar, a través de esta vía se minimiza la entrada en prisión de personas que posteriormente son condenadas a una pena no privativa de libertad o que, en caso de ser condenadas a pena privativa de libertad, se benefician de una suspensión o sustitución de esta pena. Y, en tercer lugar, y es lo que más nos interesa en este contexto, un uso limitado de la prisión preventiva favorece que los/as jueces/zas apliquen la suspensión o sustitución de la pena privativa de libertad, pues estas alternativas tendrán menos sentido cuando la persona ya haya cumplido parte de su pena en situación de prisión preventiva.

La aprobación del CP 1995 coincide con un cambio de tendencia en lo que hace al uso de la prisión preventiva por parte de los/as jueces/zas que posiblemente esté influido, junto a otros posibles factores, por la concepción más garantista de esta institución por parte de jueces/zas y tribunales, influida por la jurisprudencia constitucional sobre la materia ${ }^{10}$.

Si se analiza, la evolución de las entradas en prisión en el periodo anterior y posterior a la aprobación de CP 1995, que figura en la tabla 6, observamos dos cambios relevantes por lo que hace al uso de la prisión preventiva: por una parte, el número absoluto de entradas en prisión preventiva disminuye considerablemente y, por otra parte, del total de entradas en prisión, aumenta el porcentaje de personas que entran en prisión como condenadas, cuya mayoría posiblemente no hayan sufrido prisión preventiva previa.

\footnotetext{
${ }^{10}$ En particular resulta relevante la STC 128/1995. En Cid y Larrauri (2007) se realiza un análisis más detallado de los diversos factores que influyen en las entradas en prisión.
}

Revista Española de Investigación Criminológica

Artículo 2, Número 6 (2008) $\quad$ www.criminología.net

ISSN: $1696-9219$ 
Tabla 6. Evolución uso prisión preventiva. España (1990-2006)

\begin{tabular}{|l|lr|l|lr|}
\hline PERIODO & $\begin{array}{l}\text { ENTRADAS } \\
\text { PRISIÓN (MEDIA) }\end{array}$ & EN & $\begin{array}{l}\text { ENTRADAS EN } \\
\text { PRISIÓN PREVENTIVA } \\
\text { (MEDIA) }\end{array}$ & $\begin{array}{l}\% \text { ENTRADAS EN } \\
\text { PRISIÓN PREVENTIVA } \\
\text { SOBRE TOTAL DE } \\
\text { ENTRADAS }\end{array}$ \\
\hline $1990-1995$ & 69.397 & 58.694 & $84,6 \%$ \\
\hline $1996-2006$ & 45.611 & 30.212 & $66,2 \%$ \\
\hline
\end{tabular}

Fuente: Elaboración propia sobre la siguiente base: DGIP, Estadística General de Población Reclusa. Evolución mensual. Cataluña, Consejería de Justicia. Memòria anual y SSPRJJ, Estadístiques setmanals de població reclusa.

La evolución del uso de la prisión preventiva resulta posiblemente relevante para comprender el bajo uso de la suspensión en los años iniciales de aprobación del CP 1995. La realidad con la que se encontrarían los/las jueces/zas en los años inmediatamente posteriores a la aprobación del CP 1995 es que, en buena medida, deben resolver sobre la ejecución de penas privativas de libertad por delitos cometido con anterioridad a la entrada en vigor del CP, cuyos autores con más facilidad habrán sufrido prisión preventiva y en los que, en consecuencia, menos sentido tendrá plantearse la suspensión de la ejecución de la pena privativa de libertad.

La situación cambiará de forma importante por la interacción de dos factores: por una parte, la entrada en vigor del CP 1995 coincidirá con un menor uso de la prisión preventiva y, por otra, el nuevo Código penal ampliará las posibilidades de suspensión y sustitución de la pena privativa de libertad. Pero esta nueva realidad no se reflejará en los primeros años de entrada en vigor del Código, por cuanto entonces aún se estará principalmente ejecutando penas privativas de libertad impuestas por delitos cometidos con anterioridad a su vigencia, cuyos autores con más facilidad habrán sufrido prisión preventiva, sino a partir de los años 1998 y 1999, en los que ya se ejecutarán muchas penas privativas de libertad de personas que no habrán sufrido prisión preventiva. Es esta nueva realidad la que certificará el Registro Central de Penados y Rebeldes a partir fundamentalmente del año $2000^{11}$.

\footnotetext{
${ }^{11}$ Piénsese que es normal que un delito cometido en el año 1996 que ha sido castigado con pena privativa de libertad pueda dar lugar a un ejecución de la pena que se inscribe en el año 2000, pues según el estudio de Cid, Larrauri et al. (2002), referido a la actividad judicial en los años 1998 y 1999, entre la fecha de comisión del delito y la fecha de ejecución de la pena transcurre de media 3 años y 2 meses. A lo
}

Revista Española de Investigación Criminológica

Artículo 2, Número 6 (2008) $\quad$ www.criminología.net

ISSN: $1696-9219$ 
En síntesis, y a reserva de otras posibles explicaciones, es la combinación de dos factores -menor uso de la prisión preventiva y marco normativo más favorable a la suspensión- lo que explica que a partir de que se ejecutan las penas por delitos cometidos tras la entrada en vigor del CP 1995 se produzca un crecimiento muy significativo en el uso de la suspensión de la pena.

\subsubsection{Carencias del sistema de penas alternativas}

Aun cuando parece que la suspensión de la pena ha sido una alternativa con un uso muy importante por parte del sistema judicial y ello ha influido positivamente en la reducción de entradas en prisión, ello no quita razón al GEPC en el sentido de que ha existido una escasa aplicación del resto de penas alternativas establecidas por el CP 1995, en particular, la suspensión de la pena para drogodependientes y la sustitución. Es importante destacar que éstas son las únicas alternativas que, de acuerdo al CP 1995, pueden imponerse a personas condenadas a pena privativa de libertad que disponen de antecedentes penales. Respecto del uso de estas penas alternativas disponemos de dos tipos de datos, por una parte, el estudio de discrecionalidad judicial de Cid, Larrauri et al. (2002) y, por otra parte, las cifras sobre suspensiones con reglas de conducta que llegan a conocimiento de la administración.

El estudio sobre la aplicación de las penas alternativas a la prisión realizado por Cid, Larrauri et al. (2002), muestra que así como la suspensión ordinaria de la pena era una opción utilizada mayoritariamente por los/as jueces/zas, la suspensión de la pena para drogodependientes $\mathrm{y}$, sobre todo, la sustitución, son opciones escasamente aplicadas (Tabla 7)

cual, posiblemente, debamos sumar el tiempo que tardan los juzgados en comunicar al Registro el auto de suspensión y el tiempo que tarda el Registro en inscribirlo.

Revista Española de Investigación Criminológica

Artículo 2, Número 6 (2008) $\quad$ www.criminología.net

ISSN: 1696-9219 
Tabla 7. Uso judicial suspensión pena, suspensión pena para drogodependientes y sustitución

\begin{tabular}{|l|l|}
\hline Tipo de pena alternativa & $\begin{array}{l}\text { Porcentaje de casos en que se ha } \\
\text { aceptado (sobre casos posibles) }\end{array}$ \\
\hline Suspensión ordinaria de la pena para & $84 \%$ \\
\hline $\begin{array}{l}\text { Suspensión extraordinaria prode } \\
\text { drogodependientes }\end{array}$ & $38 \%$ \\
\hline $\begin{array}{l}\text { Sustitución de la pena privativa de } \\
\text { libertad por multa o TBC }\end{array}$ & $12 \%$ \\
\hline
\end{tabular}

Fuente: Cid, Larrauri et al. (2002)

De la misma fuente se puede extraer el dato que si bien la suspensión de la pena sirve efectivamente para evitar que una parte importante de las personas condenadas a pena privativa de libertad ingresen en prisión, en cambio, la suspensión de la pena para drogodependientes y la sustitución cumplen un papel muy pequeño respecto del citado objetivo (Tabla 8). 
Tabla 8. Ejecución penas privativas de libertad en juzgados de lo penal ${ }^{12}$.

\begin{tabular}{|l|l|l|}
\hline Sanción definitiva & Número personas & Porcentaje \\
\hline $\begin{array}{l}\text { Prisión o Arresto de fin de } \\
\text { semana ejecutados }\end{array}$ & 274 & 43,9 \\
\hline $\begin{array}{l}\text { Suspensión de la pena } \\
\text { privativa de libertad }\end{array}$ & 320 & 51,3 \\
\hline $\begin{array}{l}\text { Suspensión especial } \\
\text { drogodependientes }\end{array}$ & 13 & 2,1 \\
\hline $\begin{array}{l}\text { Sustitución pena privativa } \\
\text { de libertad }\end{array}$ & 17 & 2,7 \\
\hline $\begin{array}{l}\text { Total penas privativas de } \\
\text { libertad }\end{array}$ & 624 & 100 \\
\hline
\end{tabular}

Fuente: Cid y Larrauri (2002: 24 y 58)

Estos datos sobre escasa aplicación de la suspensión para drogodependientes y de la sustitución, encuentran corroboración, por lo que hace a la suspensión especial para drogodependientes, en las demandas de ejecución de una pena de suspensión con reglas de conducta que recibe la administración, las cuales muestran que el número de suspensiones con reglas de conducta no alcanza siquiera este $2 \%$ del total de condenas a pena privativa de libertad que muestra el estudio de Cid- Larrauri et. al. (2002) ${ }^{13}$.

\footnotetext{
${ }^{12}$ Puede sorprender las diferencias entre las cifras de suspensiones de condena de la muestra de Cid, Larrauri et.al (2002), que, como muestra la tabla 8 , se eleva al $53.4 \%$ del total de penas privativas de libertad impuestas en sentencia (sumando suspensiones ordinarias y suspensiones con reglas de conducta) y los que proporciona el Registro Central de Penados y Rebeldes, que aparecen en la tabla 5, que, para los años 2001-2005, da una media del 34\% (Tamarit 2007:29). Para entender la discordancia hay que tomar en cuenta principalmente dos cuestiones: a) El estudio de Cid, Larrauri et al. (2002) se refiere a ejecución de penas privativas de libertad referidas a delitos con pena no superior a 3 años, mientras que el Registro Central de Penados y Rebeldes toma en cuenta toda la actividad judicial, incluyendo las penas por delitos castigados con pena de prisión superior a 3 años en los que, lógicamente, la posibilidad de suspender es menor; b) por otra parte, y en sentido contrario, es posible que, según como se interpreten, los datos del Registro, minimicen en alguna medida el porcentaje de personas condenadas a los que se suspende la pena, por cuanto, lo que se anotan son penas inscritas y penas suspendidas y no personas a las que se suspende la condena. En la medida en que es más fácil que se suspenda la pena cuantas menos penas se impongan (por el límite de los dos años de la suspensión de la pena) de ello deriva que el número de autos de suspensión refleja mayor porcentaje de personas a las que se les suspende la pena que el que deriva de la comparación realizada en la tabla 5 entre penas suspendidas y penas privativas de libertad inscritas. De todo ello deriva que el porcentaje de personas condenadas a pena privativa de libertad cuya pena o penas son suspendidas se sitúa, posiblemente, en un punto intermedio entre la cifra del $53.4 \%$ que refleja el estudio de Cid, Larrauri et. al (2002) y la cifra del $34 \%$ que refleja de media el Registro entre los años 2000 y 2005.

${ }^{13}$ En el año 2004 la administración -incluyendo la administración general del Estado y la catalanarecibió aproximadamente 1.000 demandas de suspensiones de pena privativa de libertad con reglas de conducta a ejecutar, lo cual supone aproximadamente un $1.5 \%$ de la media de personas condenadas a pena privativa de libertad en los años 1996-2004. Los datos no distinguen qué porcentaje de estas suspensiones eran de drogodependientes, aun cuando hay que pensar que son la mayoría, pues en este año todavía no se advierte la reforma de la Ley de violencia de género, por lo que hace a la obligatoriedad de
}

Revista Española de Investigación Criminológica 
Las carencias del sistema de penas alternativas a la prisión por lo que hace a las personas con antecedentes penales no sólo han comportado que durante los años de aplicación del CP 2005 hayan ingresado en prisión muchas personas que, con un adecuado sistema de penas alternativas, podrían haber sido tratadas en el contexto comunitario, sino que, además, han sido aun más manifiestas, como después se indicará, a partir de la aplicación de las reformas de los años 2003 y 2004, relativas a la violencia doméstica.

\subsection{La insuficiente aplicación de los mecanismos de reinserción previstos por la legislación penitenciaria}

La tercera razón que, de acuerdo al GEPC el grupo explica la subida de las tasas de encarcelamiento consiste en que los mecanismos de reinserción previstos por la legislación penitenciaria no se están utilizando suficientemente, de manera que puedan paliar el incremento de penas derivado del CP 1995.

Si partimos de la base que el principal instrumento previsto por nuestra legislación para conseguir la liberación anticipada de las personas condenadas es la libertad condicional resulta importante analizar la evolución del uso de esta institución desde la entrada en vigor del CP 1995. Como se muestra en la tabla 9, la concesión de libertades condicional sufre un gran retroceso desde la entrada en vigor del Nuevo Código penal, sintetizado en la idea que en 2006 se conceden, en proporción al número de personas condenadas, menos de la mitad de libertades condicionales de las que se concedían en 1996. Un análisis diferenciado entre las dos administraciones competentes, muestra que la tendencia decreciente se produce tanto en Cataluña como en el territorio gestionado por la administración general del Estado, aunque, sin embargo, el número de libertades condicionales concedidas es significativamente mayor en la administración general del Estado (figura 4).

tratamiento en caso de suspensión de una pena privativa de libertad por delito relativo a la violencia de género

Fuente: Datos Administración General Estado (Valero, 2006); Datos Administración catalana (Martín 2007).

Revista Española de Investigación Criminológica

Artículo 2, Número 6 (2008) $\quad$ www.criminología.net

ISSN: $1696-9219$ 
Tabla 9: Libertad condicional. España (1996-2006)

\begin{tabular}{|c|c|c|c|}
\hline AÑO & $\begin{array}{l}\text { LIBERTADES } \\
\text { CONDICIONALES } \\
\text { CONCEDIDAS }\end{array}$ & $\begin{array}{l}\text { MEDIA DE PERSONAS } \\
\text { CONDENADAS }\end{array}$ & $\begin{array}{l}\text { LIBERTADES } \\
\text { CONDICIONALES } \\
\text { CONCEDIDAS POR CADA } \\
100 \quad \text { PERSONAS } \\
\text { CONDENADAS }\end{array}$ \\
\hline 1996 & 8.684 & 33.724 & 25.8 \\
\hline 1997 & 6.669 & 33.370 & 20.1 \\
\hline 1998 & 6.215 & 33.475 & 18.6 \\
\hline 1999 & 6.050 & 34.830 & 17.4 \\
\hline 2000 & 5.628 & 35.580 & 15.8 \\
\hline 2001 & 5.453 & 36.588 & 14.9 \\
\hline 2002 & 5.442 & 38.796 & 14 \\
\hline 2003 & 5.062 & 42.082 & 12 \\
\hline 2004 & 5.499 & 45.661 & 12 \\
\hline 2005 & 5.078 & 46.881 & 10.8 \\
\hline 2006 & 5.703 & 48.668 & 11.7 \\
\hline
\end{tabular}

FUENTE: Para libertades condicionales: Anuario estadístico de España y Generalitat de Cataluña, Consejería de Justicia, Memòria Anual. Para media de personas condenadas (tabla 1).

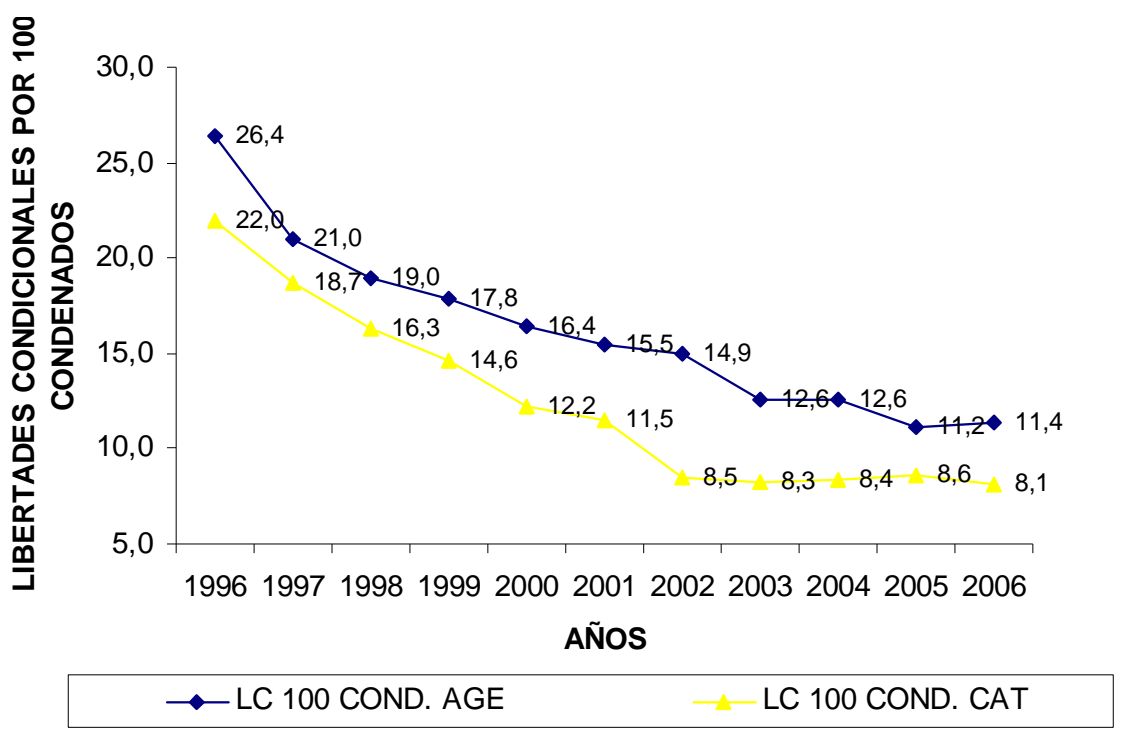

Figura 4. Libertad condicional. AGE-Cataluña (1996-2006)

Resulta importante examinar las razones de esta importante reducción en el número de libertades condicionales concedidas, existiendo, principalmente, dos posibles candidatos: el nuevo marco punitivo (que al alargar las condenas reduce el número de 
personas candidatas a la libertad condicional) y una política más restrictiva en el uso de la libertad condicional ${ }^{14}$.

Los datos de los que se disponen parecen avalar la idea que el factor básico para explicar la caída de las libertades condicionales es el nuevo marco punitivo que surge a partir del CP 1995. En 1996, antes de la entrada en vigor del CP 1995, todas las personas condenadas estaban cumpliendo condena de acuerdo a un código en que una vez cumplida entre $1 / 3$ y $1 / 2$ de la condena impuesta (dependiendo de si la persona goza de la redención ordinaria y extraordinaria o sólo da la ordinaria) ya habría extinguido los 3/4 de condena necesarios para ser candidata a la libertad condicional. Ello significa que en esta época una parte muy importante de la población reclusa cumplirá la condición temporal para poder gozar de la libertad condicional. A partir de la entrada en vigor del CP 1995 se ira reduciendo el porcentaje de personas a las que se puede conceder la libertad condicional. Ello se debe a que las personas condenadas de acuerdo al nuevo Código penal deberán extinguir, de manera efectiva, 3/4 de condena (o por lo menos 2/3) para cumplir con el requisito temporal de la libertad condicional ${ }^{15}$. De tal manera, a medida que un mayor porcentaje de la población reclusa cumpla condena con el CP 1995 se producirá una progresiva reducción de las libertades condicionales concedidas. Es esto lo que justamente se refleja en la tabla 9.

La segunda de las hipótesis consideradas sobre la reducción del número de libertades condicionales por año consiste en que a partir del CP 1995 se produce una política más restrictiva en el uso de la libertad condicional (Tébar 2006, Tamarit 2007), la cual podría haberse agravado a partir de la reforma de la ley 7/2003, que endurece las condiciones para acceder al tercer grado y a la libertad condicional (García Albero y Tamarit 2004).

Los datos de los que se disponen respecto de la forma de finalización de condena -en libertad condicional o en libertad definitiva- se refieren sólo a la administración

\footnotetext{
${ }^{14}$ La posición de que la disminución en el número de libertades condicionales también está influida por una política más restrictiva por parte de los órganos competentes está defendida por Tébar (2006) y por Tamarit (2007:30). Tébar (2006: 239) apunta, además, como otros factores que posiblemente influyen en la reducción del número de libertades condicionales, al incremento del número de personas extranjeras entre la población reclusa y a la masificación penitenciaria

${ }^{15}$ A lo que se debe añadir, como se ha mostrado, en la tabla 3, que, en referencia a algunos delitos, las penas previstas por el CP de 1995 son más largas que las previstas por el CP 1973.
}

Revista Española de Investigación Criminológica

Artículo 2, Número 6 (2008) $\quad$ www.criminología.net

ISSN: $1696-9219$ 
catalana De estos datos (expuestos en la figura 5) parece poderse extraer dos conclusiones: por una parte, no se advierte una tendencia clara a la reducción de la concesión de libertades condicionales a partir de la entrada en vigor del CP 1995; por otra parte, lo que resulta más destacable es el estancamiento en la concesión de la libertad condicional durante estos años, en lo que posiblemente influye una política restrictiva por parte de las administraciones y órganos judiciales competentes ${ }^{16}$, que la legislación restrictiva de la ley orgánica 7/2003 tiende a consolidar ${ }^{17}$.

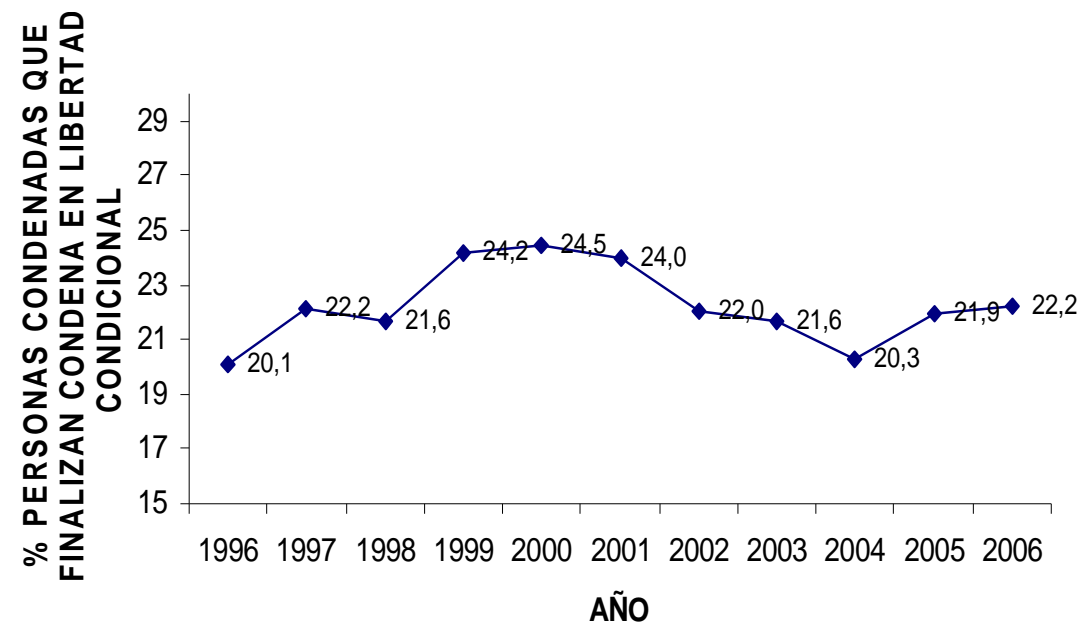

Figura 5. Personas condenadas que finalizan condena en libertad condicional. Cataluña (1996$2006)^{18}$. Fuente: Información suministrada al autor por Conselleria de Justícia, SSPRJJ.

\footnotetext{
${ }^{16}$ Para analizar las razones que influyen en la escasa concesión de la libertad condicional por parte de los órganos competentes, véase la investigación realizada por Tébar (2006), referida a la administración penitenciaria catalana.

${ }^{17}$ Sobre la incidencia de la ley 7/2003 en la política de concesión terceros grados y de libertades condicionales en la Administración General del Estado: Valero (2006), quien expone que la Administración, tras un período de reducción en la concesión de estos beneficios, habría podido recuperar los niveles anteriores. Para un análisis de la evolución de la concesión de la libertad condicional anticipada a los 2/3 de cumplimiento de condena, que ha tenido una tendencia ascendente en los últimos años, puede consultarse el citado estudio de Valero (2006) y Tébar (2006).

${ }^{18}$ Los datos de la administración general del estado sobre la forma de finalización de condena no se conocen de manera directa y sólo pueden obtenerse por extrapolación, sobre la base de los datos de la administración catalana y de las libertades condicionales en las dos administraciones. Sobre estos parámetros,se puede afirmar que en la administración general del Estado, como media durante los años analizados, aproximadamente un $29 \%$ de personas finalizan su condena en libertad condicional. Para llegar a esta conclusión procedemos de la siguiente manera: por una parte sabemos que la media finalización de condena en libertad condicional en Cataluña durante el periodo 1996-2006 es del 22.4\% (figura 5). Por otra parte, conocemos que la administración general del estado en el periodo 1996-2006 ha concedido de media un $30.4 \%$ más de libertades condicionales que la administración catalana (figura 4). $\mathrm{Si}$ aumentamos este $30.4 \%$ al $22,4 \%$, que es la media de la administración catalana, resulta que en la
}

Revista Española de Investigación Criminológica

Artículo 2, Número 6 (2008) $\quad$ www.criminología.net

ISSN: $1696-9219$ 
La misma tendencia al estancamiento en el uso de la libertad condicional se advierte en la utilización del régimen abierto que constituye un requisito previo para la concesión de la libertad condicional. El limitado recurso al régimen abierto se advierte sobre todo en la administración general del Estado ${ }^{19}$.

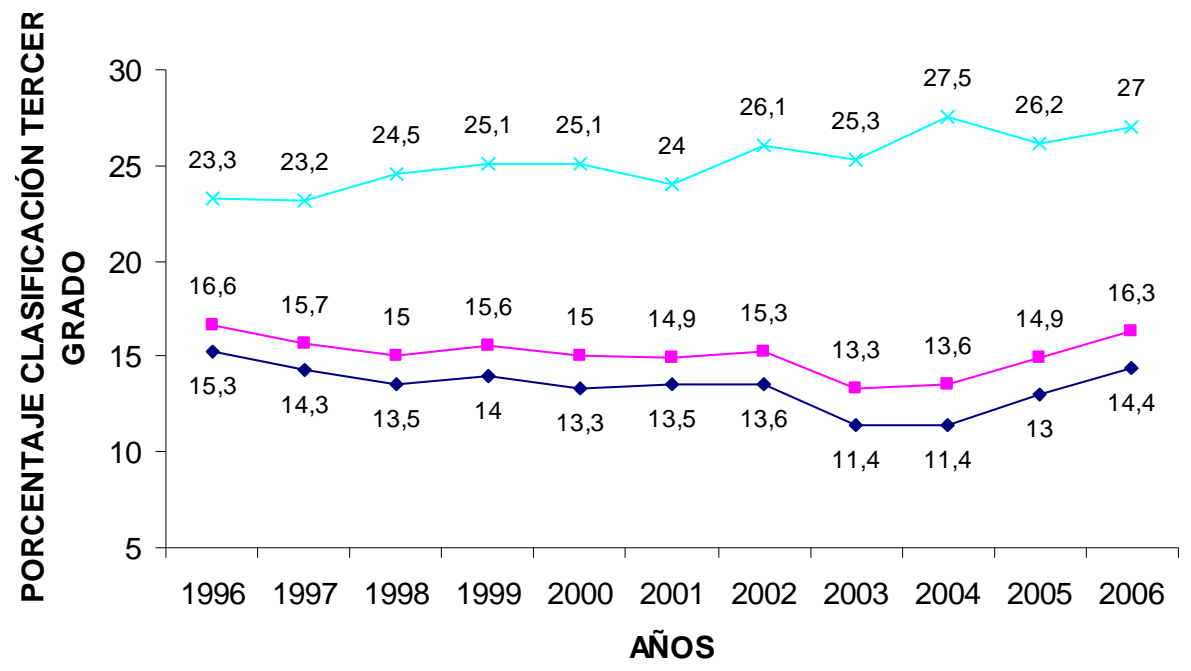

$\multimap$ CLAS. TERCER GRADO AGE $\multimap$ CLAS. TERCER GRADO. CAT. $\rightarrow$ CLAS. TERCER GRADO. ESPAÑA

Figura 6. Uso del tercer grado. España (1996-2006).

Fuente: DGIP. Estadística General de Población Reclusa. Evolución mensual; Cataluña, Conselleria de Justícia. Memòria anual y SSPRJJ, Estadístiques setmanals de població reclusa. Datos a 31 de diciembre de cada año.

En síntesis, la realidad con la que nos encontramos en España es que sólo una minoría de personas, en torno a 1/4 de la población reclusa condenada, se beneficia de los principales instrumentos de reinserción establecidos por la legislación penitenciaria, mientras que aproximadamente $3 / 4$ partes de las personas condenadas extinguen su pena

administración general del estado el $29.2 \%$ de las personas condenadas finalizan su condena en libertad condicional. En todo caso, esta cifra del $29,2 \%$ se aproxima mucho al único dato oficial del que disponemos, aportado por el Consejo de cooperación penológica, que indica que en 1999 el porcentaje de personas que finalizaron su condena en libertad condicional en la administración general del Estado fue del 31\% (información obtenida en Tébar 2006:217).

${ }^{19}$ Sobre el régimen abierto puede verse la tesis doctoral de López i Ferrer (2004), quien incide en la importancia del escaso número de plazas de régimen abierto de las que dispone la administración.

Revista Española de Investigación Criminológica

Artículo 2, Número 6 (2008) $\quad$ www.criminología.net

ISSN: $1696-9219$ 
sin que exista un regreso escalonado a la comunidad ${ }^{20}$. Por ello, puede concluirse que el GEPC está en lo cierto al advertir que el uso de los mecanismos de reinserción social en España es escaso, lo cual también contribuye a que España tengas tasas de encarcelamiento relativamente elevadas respecto de los países del entorno europeo.

\section{4. Otras causas: reformas del CP relativas a la violencia doméstica}

La mayor perspectiva desde el momento en que el Grupo de Estudios de Política Criminal realizó su manifiesto permite poner de manifiesto la incidencia de las reformas del Código penal en el 2003 y el 2004 en las tasas de encarcelamiento. Ya anteriormente, se ha discutido la incidencia de las reformas de carácter penitenciario, pero las reformas que parecen haber tenido más impacto son las referidas a la elevación a carácter de delito de determinadas conductas en el ámbito de la violencia doméstica, que han comportado una notable elevación del número de personas condenadas y, finalmente, un incremento del número de entradas en prisión en los años 2006 y 2007.

Como se ha visto en la figura 2, el número de personas condenadas por delito se ha elevado notablemente a partir del año 2003 y parece ser que el principal responsable de este incremento de condenas es justamente la elevación a carácter de delito de las conductas relativas a la violencia doméstica. En la tabla 10 se muestra la evolución de personas condenadas por delitos de lesiones y otros relativos a la violencia doméstica:

\footnotetext{
${ }^{20}$ Existe una diferencia importante -que en este trabajo no puedo profundizar- entre la Administración catalana y la administración General del Estado. En la Administración catalana, las cifras de clasificación en tercer grado y de finalización de condena en libertad condicional son bastante coincidentes e indican que un gran mayoría de las personas clasificadas en tercer grado finalizan su condena en libertad condicional. En la administración general del Estado se produce el fenómeno paradójico de que pese a tener menor número de personas clasificadas en tercer grado luego las concesiones de libertad condicional son mayores que las de la Administración catalana. Ello parece indicar -pero la cuestión requiere mayor investigación- que la administración catalana es más restrictiva que la Administración general del Estado en la concesión de la libertad condicional. Un análisis más detallado en Cid (2005b).
}

Revista Española de Investigación Criminológica

Artículo 2, Número 6 (2008) $\quad$ www.criminología.net

ISSN: $1696-9219$ 
Tabla 10. Personas condenadas por delitos lesiones/violencia doméstica. España (1996-2005)

\begin{tabular}{|l|l|l|l|l|}
\hline AÑO & $\begin{array}{l}\text { PERSONAS CONDENADAS POR } \\
\text { DELITOS DE LESIONES/VIOLENCIA } \\
\text { DOMÉSTICA }\end{array}$ & $\begin{array}{l}\% \text { SOBRE TOTAL DE PERSONAS } \\
\text { CONDENADAS }\end{array}$ \\
\hline 1996 & 3561 & 3,2 & \\
\hline 1997 & 3400 & 3,3 & \\
\hline 1998 & 3848 & 3,5 & \\
\hline 1999 & 4122 & 4,1 & \\
\hline 2000 & 4445 & 4,5 & \\
\hline 2001 & 4802 & 4,9 & \\
\hline 2002 & 5519 & 5,4 & \\
\hline 2003 & 7379 & 6,2 & \\
\hline 2004 & 21011 & 15,7 & \\
\hline 2005 & 25653 & 19,9 & \\
\hline
\end{tabular}

Fuente: INE, Estadísticas judiciales

Nota: Se incluyen personas condenadas por delitos de lesiones y por delitos contra la integridad moral (en el que el INE incluiría las condenas por delitos de violencia doméstica)

En la medida en que de acuerdo a la investigación en curso realizada por Larrauri y Antón (2007) sobre la respuesta judicial frente al maltrato en el ámbito de la pareja (art. $153 \mathrm{CP}$ ), un porcentaje aproximado del $27 \%$ del total de condenas por el art. $153 \mathrm{CP}$ consisten en prisión no suspendida, parece claro, tomando como base la estabilización de las entradas en prisión en trono a 41.000 personas en el periodo 20012005, que el incremento de entradas en prisión que se ha producido en el $2006(44,000)$ y que, de acuerdo a las proyecciones actuales, se producirá en el $2007(50,000)$ parecen buena parte explicable por el fenómeno de criminalización de la violencia doméstica, pues, como indica Larrauri “... no estamos frente a un derecho penal simbólico" (Larrauri, 2007:62).

\subsection{Síntesis}

De todo ello puede concluirse que el diagnóstico del Grupo de Estudios de Política Criminal es correcto en sentido global y puede resumirse en los siguientes tres aspectos: a) el CP de 1995 supuso un gran incremento punitivo -al elevar las penas nominales de algunos delitos y eliminar la redención de penas- y este factor, por sí sólo, explica el crecimiento de la población reclusa entre 1996-2006 de casi 20.000 personas, lo que supone un aumento del $43 \%$ en términos absolutos; b) la nueva regulación de la suspensión de la pena, y el uso que han hecho los/as jueces/zas de ella, ha contribuido de manera poderosa a la reducción del número de entradas en prisión; no obstante, ha faltado un desarrollo de los mecanismos de sustitución de la pena, aplicándose de

Revista Española de Investigación Criminológica

Artículo 2, Número 6 (2008) $\quad$ www.criminología.net

ISSN: $1696-9219$ 
manera muy limitada las vías intermedias entre prisión y suspensión de la pena para personas con antecedentes penales, que podría haber reducido ulteriormente las entradas en prisión; c) la progresiva reducción del número de libertades condicionales concedidas es un reflejo de la nueva situación punitiva basada en el alargamiento de las penas, sin que durante estos años haya existido una política dirigida a incrementar el porcentaje de personas que finalizan su condena en libertad condicional, que hubiera podido mitigar las exigencias del nuevo marco punitivo.

A todo ello debe añadirse, un último factor, que se ha manifestado recientemente y que consiste en que las reformas del 2003 y 2004 en lo referente a la elevación a la categoría de delito de las conductas de violencia doméstica los cuales ha comportado que, a partir del 2006, se haya producido un proceso de incremento de las entradas en prisión, que habían mantenido una tendencia decreciente desde 1995.

\section{Remedios}

El manifiesto del GEPC en el que se basa la propuesta de reforma del sistema de penas y su ejecución, establece que los tres pilares en los que debe basarse una reforma del sistema de penas son los siguientes (Grupo de Estudios de Política Criminal 2005: 11-12):

El principio de humanidad, que prohíbe imponer sanciones que por su duración o su forma de ejecución, supongan un sacrificio inaceptable de la persona condenada.

El principio de proporcionalidad, que obliga a diferenciar las penas en función de la gravedad de los delitos y a conservar las más aflictivas para los comportamientos delictivos más graves.

El principio de resocialización, que promueve durante la condena la reeducación de la persona y su reintegración en la comunidad. 
Sobre la base de estos principios, el GEPC elabora una propuesta que, a mi juicio, tiene tres objetivos básicos: a) evitar la entrada en prisión como primera opción por delitos no graves; b) limitar la duración efectiva de las penas; y c) mejorar las posibilidades de rehabilitación y reinserción. Lógicamente, la realización de los objetivos deberá comportar una reducción de la tasa de encarcelamiento en España.

Se realiza a continuación un análisis de las propuestas concretas realizadas por el GEPC, examinando su capacidad para lograr los citados objetivos.

a) Respecto del objetivo de evitar la entrada en prisión como primera opción si el delito no es grave el GEPC plantea dos reformas: en primer lugar poner el umbral de la suspensión y sustitución en tres años de prisión y segundo establecer un modelo individualizado de penas alternativas en que el/la juez/a pueda decidir discrecionalmente, de entre un amplio catálogo, aquélla que resulta más adecuada a las necesidades de rehabilitación de la persona. Por lo que hace a la ampliación del umbral de las penas alternativas a 3 años, y dado el gran porcentaje de penas privativas de libertad que se incluyen en este marco cabe esperar que -si se mantiene la tendencia antes referida por lo que hace al ámbito de la suspensión- se incremente significativamente el número de penas privativas de libertad que son suspendidas ${ }^{21}$. En cuanto al problema de que existan tantas entradas en prisión por delitos no graves cometidos por personas con antecedentes penales, una cuestión que parece haberse agravado a partir de las reformas penales en materia de violencia doméstica, el GEPC plantea un modelo de penas alternativas que evita la rigidez del Código Penal vigente, a través de diversas vías: no excluyendo de ninguna de las penas alternativas a las personas con antecedentes penales, configurando un amplio catálogo de penas alternativas para atender a las diversas necesidades de intervención de cada delincuente y atribuyendo al/a juez/a un poder discrecional para decidir el tipo y duración de la pena alternativa, atendiendo a sus principios inspiradores.

No obstante, para que estas propuestas, en caso de ser asumidas por el legislador, pudieran servir para reducir el encarcelamiento, se necesitaría un compromiso a dos bandas: de la administración y de la judicatura . La administración

\footnotetext{
${ }^{21}$ V. los datos del INE sobre condenas en España y el análisis que realiza Díez Ripollés (2006), que muestran que la inmensa mayoría de condenas a prisión son entre 6 meses y 4 años.
}

Revista Española de Investigación Criminológica

Artículo 2, Número 6 (2008) $\quad$ www.criminología.net

ISSN: $1696-9219$ 
debería enfatizar los programas de rehabilitación en libertad -estableciendo o potenciando los programas que atiendan a las necesidades de las personas condenadas en riesgo de reincidencia- que hoy por hoy son muy limitados ${ }^{22} \mathrm{y}$, por otra parte, se debería incidir en la cultura judicial para convencer de la existencia de estas respuestas y de su mayor efectividad respecto del uso de la prisión ${ }^{23}$.

b) En referencia al objetivo de combatir la excesiva duración de las penas privativas de libertad, la propuesta del GEPC, al establecer la pena máxima en 10 años de prisión, implica una reforma global del sistema de penas del CP. Es cierto que esta reforma no se concreta - para ello se requeriría plantear una reducción de las penas para los distintos delitos (Tamarit 2007:40)- pero lógicamente tras ella se encuentra el objetivo de que una vez desaparecida la institución de la redención de penas por el trabajo, las penas privativas de libertad se acorten de una manera que compense la eliminación de esta institución. Junto a esta propuesta, se realizan otras en el ámbito de la ejecución, como son la de hacer más flexible el sistema de tercer grado -volviendo a la situación legislativa anterior a la reforma producida por la ley orgánica 7/2003- y el de la libertad condicional, estableciendo que esta institución pueda concederse a partir de la mitad de cumplimiento de la condena y que la administración tenga obligación de elevar el expediente de libertad condicional en todos los casos antes del cumplimiento de la mitad de la condena ${ }^{24}$. El sentido de estas reformas consiste en evitar la situación actual respecto de las personas con condenas relativamente largas, respecto de las cuales, pese a que legalmente el proceso de reinserción, a través de los permisos, puede empezar a partir del cumplimiento de 1/4 de la condena cumplida, se suele retrasar este proceso en atención a considerar excesivo el tiempo restante para que la persona para alcanzar la libertad condicional (Cid 1998). Si la libertad condicional se pone como regla en la mitad de la condena será factible, para personas que no hayan tenido una

\footnotetext{
${ }^{22}$ Los programas de rehabilitación en libertad se dan sólo en el marco de la suspensión de la pena con reglas de conducta y, en determinados casos, en el marco de la pena de trabajo en beneficio de la comunidad. Datos sobre el escaso uso de estas respuestas en el sistema punitivo español en Valero (2006) y Martín (2007).

${ }^{23}$ Incidiendo en las mismas ideas: Díez Ripollés (2006:23-24). Sobre la importancia de que cualquier propuesta legislativa establezca las condiciones para que pueda ser aplicada por jueces/zas y tribunales, véase el trabajo de este mismo autor (2003: 95-96).

${ }^{24}$ Para evitar la situación, detectada en el trabajo de Tébar (2006), de que respecto de una parte de las personas condenadas la administración no eleve al juzgado de vigilancia penitenciaria el expediente de libertad condicional.
}

Revista Española de Investigación Criminológica

Artículo 2, Número 6 (2008) $\quad$ www.criminología.net

ISSN: $1696-9219$ 
clasificación inicial en tercer grado, que en mayor número de casos se pueda empezar el proceso de reinserción a partir del 1/4 de condena.

No obstante, el hecho de que exista un marco normativo más favorable a la concesión de los mecanismos de reinserción social no es, por sí sólo, una garantía de que éstos van a concederse en mayor medida que en la actualidad. Ya anteriormente se ha señalado que la tasa de personas que actualmente gozan de sistemas de reinserción en la comunidad durante el cumplimiento de la condena -a través del régimen abierto y de la libertad condicional- se sitúa en torno al 1/4 de la población reclusa condenada. Para conseguir que este porcentaje aumente significativamente, además de un marco normativo más favorable, se requiere principalmente enfatizar los recursos que se dedican al proceso de preparación de la vida en libertad que son muy limitados comparativamente a los que se dedican a las instituciones cerradas (López y Ferrer 2004) y, contemporáneamente, repensar una práctica penitenciaria que parece concebir más bien el acceso al tercer grado y a la libertad condicional como un privilegio que como una transición necesaria a la liberación acorde al fundamento resocializador de esta institución (Tébar 2006:242).

c) El tercer objetivo básico de la propuesta del GEPC consiste en mejorar las oportunidades de rehabilitación y de reinserción durante el cumplimiento de la pena privativa de libertad. En la medida en que se parte de que el proceso de reinserción social debe ir acompañado de un proceso de rehabilitación, se pretende garantizar que toda persona condenada a prisión pueda disponer de un programa de rehabilitación que atienda a sus necesidades criminógenas, corrigiendo la actual situación en la que parece que sólo una minoría de personas se benefician de programas específicos de rehabilitación dentro de prisión o de programas de reinserción en el exterior (Cid 2005b). Esta propuesta del grupo se canaliza tanto en el ámbito institucional, en el que se propone que se incrementen los recursos para programas específicos de rehabilitación, que puedan ayudar a la persona a presentar un buen pronóstico, de cara a conseguir el régimen abierto o la libertad condicional, como en el ámbito del tercer grado y la libertad condicional, exigiendo que el cumplimiento de la pena en estas situaciones vaya acompañada de la necesaria supervisión rehabilitadora. 
En principio la propuesta del GEPC parece capaz de conseguir el resultado propuesto -en el sentido de que favorecer los recursos destinados a rehabilitación parece lógico que pueda beneficiar los procesos de reinserción y con ello reducir el encarcelamiento- y posiblemente el mayor obstáculo sea, como en el caso anterior, el económico, pues la implementación de estos programas de rehabilitación -como, por ejemplo, los de trabajo retribuido en el exterior- representan un coste importante para la administración.

\section{Discusión}

Una propuesta reduccionista como la realizada por el GEPC en su proyecto sobre "El sistema de penas y su ejecución y la medidas cautelares" corre el riesgo de ser vista por los responsables políticos como una opción inspirada exclusivamente en principios humanitarios pero no comprometida con la lucha contra la delincuencia. Más allá de que los principios humanitarios - entendiendo el principio de humanidad como no imponer castigos innecesarios- deberían ser un patrimonio de cualquier país civilizado, creo que es importante responder a esta posible objeción, mostrando que el proyecto del GEPC tiene mejores potencialidades de servir a la lucha contra la delincuencia que el sistema punitivo que se critica. Ello se advierte en las tres propuestas que plantea el grupo para invertir la tendencia a la expansión del encarcelamiento.

a) La propuesta de ampliar las posibilidades de imponer penas alternativas no sólo pretende evitar entradas innecesarias en la prisión sino también reducir las mayores tasas de reincidencia de las personas condenadas a penas cortas de prisión, comparativamente a las condenadas a penas alternativas (Cid 2007). Para ello se diseña un sistema de penas alternativas capaz de afrontar las necesidades criminógeneas de las personas en los casos en que sea necesario ${ }^{25}$.

\footnotetext{
25 El proyecto de Código Penal de 2007, que por otra parte realiza una regulación del sistema de suspensión y sustitución de la pena en el que se incorporan algunas ideas del GEPC, se opone a la propuesta del GEPC al excluir de penas alternativas, con pocas excepciones, a delincuentes reincidentes y habituales y al establecer medidas para dificultar el uso del tercer grado y libertad condicional de esta clase de delincuentes. Estas medidas restrictivas parecen poco justificables atendiendo a la literatura criminológica que destaca que justamente es con personas de alto riesgo de reincidencia con las que existe más necesidad de intervención y que esta intervención tiene más posibilidades de ser efectiva si es en el ámbito comunitario (McGuire 2005).
}

Revista Española de Investigación Criminológica Artículo 2, Número 6 (2008) $\quad$ www.criminología.net

ISSN: 1696-9219 
b) La reducción de la duración efectiva de las condenas no sólo trata de limitar los costes humanos y económicos del encarcelamiento, sino que el desarrollo de programas de reinserción en el periodo de transición entre la privación de libertad y la libertad definitiva se consiga reducir la tasa de reincidencia de las personas encarceladas (Luque, Ferrer y Cadevila 2004). Contrariamente a lo que suele presumirse en círculos no criminológicos, no es el cumplimiento efectivo de la condena lo que va a proteger a la sociedad de futura delincuencia, sino que lo que tiene mayor posibilidad de conseguirlo es un regreso a la comunidad apoyado socialmente, realizado a través, principalmente, de los mecanismos del tercer grado y de la libertad condicional $\left(\right.$ Petersilia 2003) ${ }^{26}$

c) El apoyo a programas de rehabilitación dentro de la prisión que puedan abordar algunas necesidades criminógenas de la persona, los cuales deberán ir vinculados a programas en el exterior, no debe ser visto como algo que sólo favorece a la propia persona condenada, en cuanto le ayuda a superar problemas, sino que debe también ser valorado por el beneficio social que reporta al poderse reducir la tasa de reincidencia.

${ }^{26}$ Sobre la comparación de las tasas de reincidencia entre personas que extinguen su condena en libertad definitiva o en libertad condicional, véase: Luque, Ferrer y Capdevila (2004). 


\section{Referencias}

Cid, J. (1998). Derecho a la reinserción social (A propósito de la reciente jurisprudencia constitucional en materia de permisos). Jueces para la democracia 32: 3648.

- (2005a). La suspensión de la pena en España: descarcelación y reincidencia. Revista de Derecho Penal y Criminología 15, 223-39.

- (2005b). The Penitentiary System in Spain. The Use of Imprisonment, Living Conditions and Rehabilitation. Punishment and Society 7, 147-66

- (2007). ¿Es la prisión criminógena? (Un análisis comparativo de reincidencia entre la prisión y la suspensión de la pena). Revista de Derecho Penal y Criminología 19, 469-98 (en curso de publicación).

Cid, J. (Coord.), Larrauri, E. (Coord.), Escobar, G., Lahoz, J., López i Ferrer, M., Tébar, B. y Varona, D. (2002). Jueces penales y penas en España. (Aplicación de las penas alternativas a la privación de libertad). Valencia: Tirant lo blanch.

- Cid, J y Larrauri, E. (2007). Development of crime, social change, mass media, crime policy, sanctioning practice and their impact on prison population rates. National Report: Spain, En curso de publicación.

Díez Ripollés, J. L. (2003). La racionalidad de las leyes penales. Madrid:Trotta.

- (2006): "La evolución del sistema de penas en España: 1975-2003", Revista Electrónica de Ciencia Penal y Criminología, 08-07:1-25.

García Albero, R y Tamarit, J. M. (2004). La reforma de la ejecución penal. Valencia:Tirant lo Blanch.

Grupo de Estudios de Política Criminal (2005). Una propuesta alternativa al sistema de penas y su ejecución, y a las medidas cautelares personales. Málaga: Grupo de Estudios de Política Criminal.

Larrauri, E. (2007). Criminología Crítica y Violencia de Género. Madrid:Trotta.

Larrauri, E. and Antón, L. (2007). La aplicación de la pena en los delitos de violencia doméstica. Investigación en curso.

López i Ferrer, M. (2004). Cárceles abiertas, Tesis doctoral leída en la Universidad Autónoma de Barcelona, julio 2004, no publicada.

Luque, E., Ferrer- M. y Capdevila. M. (2004). La reincidència penitenciaria a Catalunya. Barcelona: Centre d'Estudis Jurídics i Formació Especialitzada.

Martín, J. (2007). Probation and probation services in Catalonia. A. van Kalmouth (ed), Probation and probation services. En curso de publicación.

McGuire, J. (2005). El reanacimiento de los programas de rehabilitación en medio abierto. En J. Cid y E. Larrauri (coord.) La delincuencia violenta: ¿Prevenir, castigar o rehabilitar?, Valencia: Tirant lo Blanch, pp. 96-145.

Navarro C. (1997). La reducción de beenficios penitencarios en la legislación vigente. En J. Cid y E. Larrauri (coord.). Penas alternativas a la prisión. Barcelona: Bosch, 1997, pp. 225-50

Petersilia, J. (2003). When Prisoners come Home. Parole and Prisoner Reentry. Oxford:OUP.

Tamarit, J. M. (2007). Sistema de sanciones y política criminal. Revista Española de Ciencia Penal y Criminología 09-06.

http://criminet.ugr.es//recpc

Tébar, B. (2006): El modelo de libertad condicional español. Pamplona:Aranzadi.

Revista Española de Investigación Criminológica

Artículo 2, Número 6 (2008) $\quad$ www.criminología.net

ISSN: $1696-9219$ 
Valero, V. (2006). Repercusiones de la política criminal en el sistema de ejecución de penas. Ponencia a: Congres Penitenciari Internacional. La funció social de la política penitenciaria. Barcelona (2006)

www.gencat.cat/justicia/doc/doc_45214166_1.pdf

Varona, D. (2004). La reforma de las penas no privativas de libertad (LO 15/2003): ¿Una paso adelante en el sistema de penas alternativas a la prisión?. Revista española de investigación criminológica 4. 